\title{
Análise de eficiências técnica e de escala das indústrias do Pólo Moveleiro de Ubá
}

Ana Cristina Miranda Rodrigues
Mestranda em Administração pela Universidade Federal de Viçosa - UFV
Rua Três, 475 / 102. Bairro Santo Antônio. Viçosa/MG
CEP: 36570-000
E-mail: rodrigues_81@hotmail.com
Suely de Fátima Ramos Silveira
Professora da Universidade Federal de Viçosa - UFV
Av. P. H. Rolfs s/n, Centro. Viçosa/MG. CEP: $36570-000$

E-mail:sramos@ufv.br

Daphine Alberti de Freitas

Graduanda em Administração pela Universidade Federal de Viçosa - UFV

Rua José Valentino Cruz, 65. Centro. Viçosa/MG. CEP: 36570-000

E-mail: daphinealberti@yahoo.com.br

Luiz Antônio Abrantes

Doutor em Administração, Universidade Federal de Lavras - UFLA Professor da Universidade Federal de Viçosa - UFV

Av. P. H. Rolfs s/n, Centro. Viçosa/MG. CEP: $36570-000$

E-mail: abrantes@ufv.br

Marco Aurélio Marques Ferreira

Doutor em Economia Aplicada pela Universidade Federal de Viçosa - UFV

Professor da Universidade Federal de Viçosa - UFV

Av. P. H. Rolfs s/n, Centro. Viçosa/MG. CEP: 36570-000

E-mail:marcoaurelio@ufv.br

\section{RESUMO}

As organizações devem conhecer os custos e as despesas de suas operações para estruturar um modelo de formação de preços e tomar decisões mais acertadas, além de estabelecer estratégias de segmentação de mercado e gerar lucro. Entretanto, as indústrias do setor moveleiro de pequeno e médio portes, como, também, as microempresas desta atividade, tendem a ter alguma estrutura de controle de custos, porém, não totalmente sistematizada. Considerando a relevância do Pólo Moveleiro de Ubá, onde existe a predominância de indústrias desses portes, uma questão foi levantada: Qual o nível de eficiência dessas indústrias? O objetivo deste trabalho foi, portanto, 
analisar as eficiências técnica e de escala das indústrias do Pólo Moveleiro de Ubá, em 2007, a partir dos custos de produção. Constatou-se que das 33 indústrias moveleiras analisadas, 4 não apresentaram problema de escala, porém não podendo aumentar 0 faturamento sem elevação dos custos de produção. Em relação às empresas ineficientes, 10 apresentaram apenas problemas de eficiência de escala, com a correta utilização dos insumos (custos de produção), e 19 apresentaram problemas de excesso de insumos e problemas de escala. Os resultados ainda indicaram que as empresas ineficientes poderiam aumentar o faturamento: (a) em 19\%, caso utilizassem adequadamente os insumos; e (b) em $28,4 \%$ com os mesmos insumos, se estivessem operando em escala correta.

Palavras-chaves: Indústria moveleira. Custos de produção. Análise de Eficiência.

\title{
Technical and scale efficiences analysis of furniture industries from the market pool of Ubá city
}

\begin{abstract}
The organizations must know their operational costs and expenses in order to structure a model for prices formation and take better decisions, besides establishing market strategies and making profits. Although, the small and medium industries from furniture market, and also the micro-companies which work with furniture, tend to have some kind of structure of cost control, however, not totally formed. Considering the furniture market pool from Uba city, which is composed basically of those kinds of industries, one question is asked: What is the efficiency level of those industries? The objective of this paper is to analyze the technical efficiency of the furniture companies from Uba city, in 2007, based on their production costs. It is noticed that from the 33 analyzed companies, 4 of them didn't present any scale problems, but they couldn't raise the profits with raising the production costs. When it comes to the inefficient companies, 10 present only scale efficiency problems, with the correct use of inputs (production costs), and 19 present problems inputs excess and scale problems. The results also indicated that inefficient companies could raise the profits (a) in $19 \%$, in case they use correctly their inputs; and (b) in $28,4 \%$ with the same inputs, if they were operating in correct scale.
\end{abstract}

Key Words: Furniture industry. Production costs. Efficiency analysis.

\section{INTRODUÇÃO}

A gestão de custos se apresenta como uma das principais ferramentas de planejamento, análise e controle das atividades operacionais das empresas, visando à maximização dos resultados econômico-financeiros. Para isso, as organizações devem 
conhecer seus custos e despesas operacionais, estruturando seu modelo de formação de preços, tomando decisões mais acertadas, estabelecendo estratégias de segmentação de mercado e, finalmente, gerando lucro.

Os custos tornam-se altamente relevantes quando da tomada de decisões em uma empresa. Isto porque, devido à alta competição, as empresas já não podem mais definir seus preços de acordo com os custos incorridos, e sim, com base nos preços praticados no mercado em que atuam (Franco, 1996).

$\mathrm{Na}$ indústria do setor moveleiro, como em outros setores industriais, o processo de gestão de custos está centrado na cadeia produtiva, iniciando no projeto e desenho do produto, passando pelo processo de fabricação, marketing, vendas, distribuição, assistência técnica e culminando com a retirada do mercado.

A indústria moveleira brasileira, assim como em outros países, está organizada em clusters e apresenta produção geograficamente dispersa por todo território nacional, localizando-se principalmente na região Centro-Sul do país, que responde por $90 \%$ da produção nacional e $70 \%$ da mão-de-obra do setor. Os principais pólos estão assim distribuídos: Grande São Paulo (SP), Bento Gonçalves (RS), Lagoa Vermelha (RS), São Bento do Sul (SC), Arapongas (PR), Ubá (MG), Votuporanga e Mirassol (SP), respectivamente, com uma estrutura bastante fragmentada (Abimóvel, 2006; IBGE, 2008).

O setor moveleiro de Minas Gerais apresentou elevação de 53,99\% no faturamento, de 2004 para 2005. O Estado ainda participou, em 2005, com 1,13\% no mercado de exportações do ramo moveleiro do Brasil (Abimóvel, 2006). O Pólo Moveleiro de Ubá, especificamente, apresentou, nos últimos quinze anos, uma elevada taxa de crescimento.

Esse nível de atuação torna as indústrias moveleiras do Estado um importante segmento na economia do Brasil, gerando movimento econômico, empregos, contribuição de tributos e encargos sociais. Diante desse mercado e da competitividade globalizada, entende-se que esse ramo empresarial necessita de adequados métodos de gestão em custos.

Eidt (2006) acrescenta que as indústrias do setor moveleiro de médio porte 
tendem a ter alguma estrutura de controle, porém, não totalmente sistematizado, comportamento este diferenciado das indústrias do setor moveleiro de grande porte, que tendem a ter gestão de custos por necessidade de seus volumes de produção e negócios.

Em função disso, uma questão é levantada: Qual o nível de eficiência das indústrias moveleiras de Ubá? Assim sendo, este trabalho tem como objetivo analisar as eficiências técnica e de escala das indústrias do Pólo Moveleiro de Ubá.

\section{REFERENCIAL TEÓRICO}

\subsection{A importância da gestão de custos}

A atividade industrial difere da atividade comercial pela complexidade das operações, pois as empresas industriais compram mercadorias (matéria-prima) de várias espécies e as transformam em novos produtos, agregando os demais fatores da produção, cujo custo total de produção forma o valor dos estoques, e pela venda identifica-se o custo dos produtos vendidos (Eidt, 2006).

Hansen e Mowen (2001) consideram que, apesar de os custos de atividades e processos não aparecerem nas demonstrações financeiras, conhecê-los é fundamental para a concorrência das empresas, cujo foco é competir por espaço e permanecer no mercado. Assim, o desempenho e o resultado das empresas estão fortemente vinculados ao processo de gestão de custos em qualquer atividade econômica.

No entanto, Khoury e Ancelevicz (1999) afirmam que são poucas as pequenas e médias empresas no Brasil, que aplicam técnicas de custeio. Isso se deve, principalmente, à carência que estas têm de um bom sistema de informação.

As indústrias consumidoras em escala de materiais e componentes para produtos, como também de uma cadeia sucessiva de custos para gerir as atividades industriais, precisam estruturar e implantar um sistema de apuração de custos desses componentes, para obter informações do quanto custam seus produtos e atividades. Uma das importantes causas dos maus resultados financeiros e do insucesso da empresa é a falta de conhecimento dos custos de seus produtos (Dudick, 1974).

Eidt (2006) afirma que os custos precisam ser gerenciados e conduzidos de tal 
forma que cada operação de consumo contribua no resultado da empresa, independente de serem constituídos por pequenos valores individuais. Além disso, a lucratividade nem sempre se realiza pelo aumento dos preços, uma vez que nem toda pretensão de aumentar o preço é exequível, mas, principalmente, pela economia e redução de custos e despesas.

\subsection{Considerações sobre eficiência}

O conceito de eficiência em administração advém da aceitação de que as organizações são sistemas abertos que influenciam e são influenciados pelo meio em que estão inseridos. Segundo Oliveira (2002), os elementos que compõem este sistema são: os objetivos dos usuários do sistema e do próprio sistema; as entradas, que fornecem o material e a energia para o processamento; o processamento em si, que transforma o insumo (entrada) em produto; as saídas correspondentes ao resultado do processo. Para o autor, eficiência é uma medida de rendimento individual dos componentes do sistema.

Considerando os insumos produtivos, o sistema empresa é eficiente quando consegue gerar o máximo de produtos com a tecnologia produtiva existente ou quando se consome o mínimo de insumos, mantendo-se o mesmo nível de produtos.

Ferreira (2005) afirma que a eficiência é tratada na administração como uma medida de rendimento global desses sistemas abertos. Daí a eficiência técnica ser chamada de eficiência produtiva ou medida de produtividade legal. Segundo o autor, a eficiência está nas condições de operacionalização do sistema, ou seja, na melhor utilização das entradas para maximizar as saídas, considerando a tecnologia disponível.

Segundo Gomes e Baptista (2004), a eficiência é separada em dois componentes: eficiência técnica, que reflete a habilidade da firma em obter máximo produto, dado um conjunto de insumos; e eficiência alocativa, que reflete a habilidade da firma em utilizar os insumos em proporções ótimas, dados seus preços relativos. Essas duas medidas constituem a medida de eficiência econômica total.

De acordo com Miller (1981), a eficiência técnica é a relação entre o produto e os insumos, sendo medida pelas unidades físicas do produto comparadas às unidades 
físicas dos insumos. Assim, a eficiência é uma medida de desempenho relativa, sendo que a melhor prática é tida como parâmetro para análise dos demais casos.

Ferreira (2005) ressalta a importância de considerar que a eficiência econômica é uma extensão da eficiência técnica, sendo a primeira condição indispensável para se atingir a segunda. Isso porque, enquanto a eficiência técnica está preocupada com o aspecto físico da produção, a eficiência econômica se preocupa com os aspectos físico e monetário da produção.

Sob a pressuposição da economia, a eficiência se refere à otimização dos recursos e à falta de desperdícios, ou seja, a máxima utilização dos recursos disponíveis para satisfazer as necessidades dos indivíduos e das organizações (Pindyck e Rubinfeld, 2005).

Ferreira (2005) acrescenta que, na literatura econômica, as medidas de eficiência são normalmente representadas por uma função de fronteiras, sendo eficientes as firmas que se posicionam sobre essa fronteira, pois essas empresas conseguem maximizar a produção, mesmo com restrições.

\section{METODOLOGIA}

\subsection{Análise Envoltória de Dados (DEA)}

Em ciências sociais aplicadas e, de forma especial, em Finanças e em Custos, as medidas de eficiência são normalmente representadas por uma função de fronteiras construídas no sistema de coordenadas, em que as firmas eficientes posicionam-se necessariamente sobre a fronteira, embora, diante da existência de desperdícios, nem todas as firmas sobre a fronteira sejam eficientes.

Os modelos de análise envoltória de dados (DEA) são técnicas utilizadas para analisar a eficiência relativa de diferentes unidades produtoras, conhecidas como DMU (decision making unit), na abordagem de análises sobre fronteiras. O objetivo da DEA é construir um conjunto de referências a partir dos dados das DMUs e, então, classificálas em eficientes ou ineficientes, tendo como referencial essa superfície formada. Assim, uma pressuposição fundamental na técnica DEA é a de que, se uma DMU A é capaz de produzir $Y(A)$ unidades de produto utilizando $X(A)$ unidades de insumos, 
outras DMUs também podem fazê-lo, caso estejam operando eficientemente. A medida de eficiência é relativa e o respectivo valor para uma unidade de produção corresponde ao desvio observado em relação àquelas unidades consideradas eficientes (Gomes e Baptista, 2004).

Entretanto, os autores afirmam que, embora a análise de função de produção e eficiência, pela abordagem de programação matemática, já tenha começado antes dos anos 1970, foi o trabalho de Charnes et al. (1978) que introduziu na literatura o termo Data Envelopment Analysis (DEA), técnica não-paramétrica que utiliza a programação matemática para analisar a eficiência relativa das unidades de produção.

De acordo com Triola (2005), as técnicas não-paramétricas são aquelas que não exigem suposições sobre as distribuições populacionais, podendo ser aplicadas a uma grande variedade de situações.

Segundo Charnes et al. (1994), para estimar e analisar a eficiência relativa das DMUs, a DEA utiliza a definição de ótimo de Pareto, segundo o qual nenhum produto pode ter sua produção aumentada sem que sejam aumentados os seus insumos ou diminuída a produção de outro produto, ou, de forma alternativa, quando nenhum insumo pode ser diminuído sem ter que diminuir a produção de algum produto. $O$ autor reforça que a eficiência é analisada, relativamente, entre as unidades.

Assim, para a execução dos modelos DEA, são necessários dados referentes aos insumos e produtos de cada DMU a ser analisada. Cooper et al. (2000) identificam alguns pontos para auxiliar na escolha dos dados, como: os dados não devem assumir valores negativos; os insumos, os produtos e a escolha das DMUs devem refletir 0 interesse do pesquisador; a unidade de medida dos insumos e produtos não necessita ser a mesma; e, preferencialmente, o número de variáveis (soma de insumos e produtos) não deve superar em um terço o número de observações (Gomes e Baptista, 2004).

Assim, a busca da fronteira de eficiência para cada DMU, especificamente, proporcionará a identificação daquelas com desempenhos utilizados como referência para as demais DMUs da amostra (Ferreira, 2005).

Parece, portanto, apropriado o emprego da DEA neste estudo, considerando 
que as indústrias do Pólo Moveleiro se apresentam com objetivos semelhantes e utilizam o mesmo conjunto de fatores de produção para a geração de resultados.

Gomes e Baptista (2004) apontam que as avaliações das medidas de eficiência podem ser precedidas de duas orientações: (a) orientação insumo, que consiste na redução de insumos;

Ferreira (2005) acrescenta que a orientação para insumo busca por redução máxima dos níveis de insumo, mantendo constante o nível do produto, e a orientação produto procura maximizar o aumento proporcional nos níveis do produto, mantendo fixa a quantidade de insumos. Assim, a eficiência reflete a habilidade de uma unidade produtiva, sob um dado conjunto de insumos, obter o máximo produto ou, de outra forma, dado um nível de produção, obter a menor utilização de insumos.

As medidas de eficiência orientadas para insumo procuram responder à seguinte pergunta: "Qual a quantidade de insumos que pode ser proporcionalmente reduzida, sem alterar a quantidade de produto que está sendo produzido? ". Por outro lado, a análise de medidas de orientação produto a procura responder à seguinte questão: "Qual a quantidade de produto que poderia ser proporcionalmente expandida sem alterar as quantidades de insumos utilizados?" (Coelli, 1998, apud Gomes e Baptista, 2004). Assim, optou-se, neste estudo, por trabalhar com medidas de eficiência orientadas para o produto.

Os Gráficos (a) e (b) da Figura 1 ilustram as medidas de eficiência com orientação insumo e com orientação produto, respectivamente.

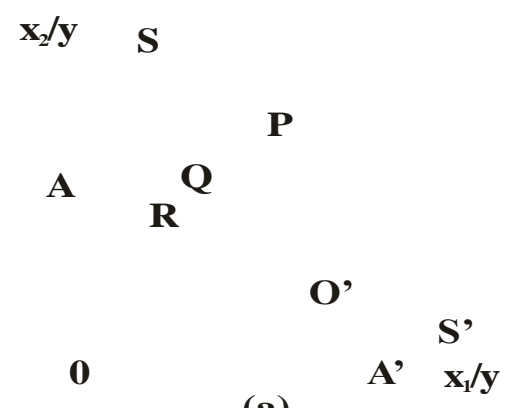

(a)

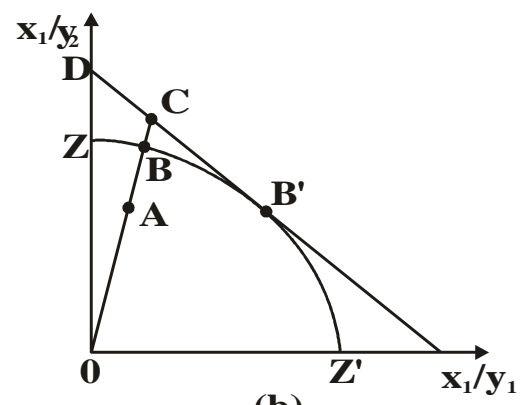

(b)

Figura 1 - Medidas de eficiência com orientação insumo (a) e orientação produto (b). Fonte: Adaptada de Gomes e Baptista (2004) 
Análise de eficiências técnica e de escala das indústrias do Pólo Moveleiro de Ubá Ana Cristina Miranda Rodrigues, Suely de Fátima Ramos Silveira, Daphine Alberti de Freitas, Luiz Antônio Abrantes, Marco Aurélio Marques Ferreira

Segundo Mello et. al. (2003), o peso para cada fator de ponderação (insumos e produtos) é obtido por meio da resolução de um problema de programação fracionária, em que cada unidade analisada maximize sua eficiência.

Assim, considerem-se $\mathrm{k}$ insumos e $\mathrm{m}$ produtos para cada $\mathrm{n}$ DMUs. São construídas duas matrizes: a matriz $X$ de insumos, de dimensões $(k \times n)$ e a matriz $Y$ de produtos, de dimensões $(m \times n)$, representando os dados de todas as $n$ DMUs. $\mathrm{Na}$ matriz $X$, cada linha representa um insumo e cada coluna representa uma DMU. Já na matriz $\mathrm{Y}$, cada linha representa um produto e cada coluna uma DMU. Para a matriz $\mathrm{X}$, é necessário que os coeficientes sejam não- negativos e que cada linha e cada coluna contenham, pelo menos, um coeficiente positivo, isto é, cada DMU consome ao menos um insumo e uma DMU, pelo menos, consome o insumo que está em cada linha. O mesmo raciocínio se aplica para a matriz Y.

Assim, para a i-ésima DMU, são representados os vetores xi e yi, respectivamente, para insumos e produtos. Para cada DMU, pode-se obter uma medida de eficiência, que é a razão entre todos os produtos e todos os insumos. Para a i-ésima DMU tem-se:

$$
\text { Eficiência da DMU } i=\frac{u^{\prime} y_{i}}{v^{`} x_{i}}=\frac{u_{1} y_{1 i}+u_{2} y_{2 i}+\Lambda+u_{m} y_{m i}}{v_{1} x_{1 i}+v_{2} x_{2 i}+\Lambda v_{k} x_{k i}}
$$

em que u é um vetor ( $m \times 1)$ de pesos nos produtos e vé um vetor $(k \times 1)$ de pesos nos insumos. Note que a medida de eficiência será uma escala, devido às ordens dos vetores que a compõem. 
Segundo Gomes e Baptista (2004), o cálculo da eficiência dessa forma pressupõe a aplicação de um conjunto comum de pesos em todas as DMUs. Apesar disso, existe dificuldade em obter um conjunto comum de pesos para determinar a eficiência relativa de cada DMU. Isto porque, as DMUs podem estabelecer valores para os insumos e produtos de modos diferentes, e, então, adotarem diferentes pesos. Torna-se necessário, portanto, estabelecer um problema que permita que cada DMU possa adotar o conjunto de pesos que for mais favorável comparado às outras unidades. Para selecionar os pesos ótimos para cada DMU, especifica-se um problema de programação matemática, conforme abaixo.

$$
\begin{array}{ll}
\operatorname{MAX}_{u, v} \quad\left(\mu^{\prime} y_{i} / v^{\prime} x_{i}\right), \\
\text { sujeito } a: \\
\\
\mu^{\prime} y_{j} / v^{\prime} x_{j} \leq 1, j=1,2, \ldots, n . \\
& \mu, v \geq 0,
\end{array}
$$

Esta formulação envolve a obtenção de valores para $\mu$ e $v$, de forma que a medida de eficiência para a i-ésima DMU seja maximizada, sujeita à restrição de que as medidas de eficiência de todas as DMUs sejam menores ou iguais a um. Caso a eficiência obtida para a DMU testada seja igual a um, ela será eficiente em relação às demais; caso contrário, será ineficiente, pois existem DMUs que combinam mais eficientemente os seus insumos e produtos.

Entretanto, Gomes e Baptista (2004) citam Charnes et al. (1978) afirmando que a solução em (2) é uma formulação de programação não-linear estendida de um problema de programa fracionário, sendo necessária a transformação deste problema, com infinitas soluções possíveis, em um problema de programação linear, com uma única solução. Essa transformação permitirá a utilização de um grande número de observações (DMUs) e um número menor de insumos e produtos. Dessa forma, a formulação linearizada é a seguinte: 
Análise de eficiências técnica e de escala das indústrias do Pólo Moveleiro de Ubá Ana Cristina Miranda Rodrigues, Suely de Fátima Ramos Silveira, Daphine Alberti de Freitas, Luiz Antônio Abrantes, Marco Aurélio Marques Ferreira

$$
\operatorname{MAX}_{u, v} \quad\left(\mu^{\prime} y_{i} / v^{\prime} x_{i}\right)
$$

sujeito $a$ :

$$
\begin{aligned}
& \mu^{\prime} y_{j} / v^{\prime} x_{j} \leq 1, j=1,2, \ldots, n . \\
& v x_{i}=1 ; \mu, v \geq 0
\end{aligned}
$$

Segundo Bowlin (1998), o modelo apresentado objetiva maximizar a produção virtual, mantendo a condição de que esta produção não pode exceder os insumos virtuais em nenhuma DMU.

\subsubsection{Modelos com orientação produto e pressuposição de retornos variáveis à escala}

De acordo com Gomes e Baptista (2004), existem dois modelos clássicos de DEA com orientação para o produto e para o insumo: o CCR, com retornos constantes à escala, desenvolvido por Charnes, Cooper e Rhodes; e o BCC, com retornos variáveis à escala, desenvolvido por Banker, Charnes e Cooper. Segundo os autores, 0 modelo de retornos constantes à escala (CCR) pode ser reformulado com o objetivo de possibilitar retornos variáveis às DMUs analisadas $(B C C)$. A ideia é introduzir uma restrição de convexidade ao modelo CCR, apresentado em (4). 


$$
\begin{array}{ll}
\operatorname{MAX}_{\phi, \lambda} & \phi, \\
\text { sujeito } & a: \\
& -\phi y_{i}+Y \lambda \geq 0, \\
& x_{i}-X \lambda \geq 0, \\
& \lambda \geq 0,
\end{array}
$$

em que yi é um vetor $(m \times 1)$ de quantidades de produto da i-ésima DMU; xi é um vetor ( $\mathrm{k} \times 1$ ) de quantidades de insumo da i-ésima DMU; Y é uma matriz ( $\mathrm{n} \times \mathrm{m}$ ) de produtos das n DMUs; $X$ é uma matriz ( $\mathrm{n} \times \mathrm{k}$ ) de insumos das $\mathrm{n}$ DMUs; $\square$ é um vetor $(\mathrm{n} \times 1)$ de pesos; $\theta$ é uma escalar, cujo valor será a medida de eficiência da i-ésima DMU. Caso o valor de $\theta$ seja igual a 1, a DMU será eficiente; caso contrário, será menor que um. 0 parâmetro $\lambda$ é um vetor ( $n \times 1)$, cujos valores são calculados de forma a obter a solução ótima. Para uma DMU eficiente, todos os valores de $\lambda$ serão zero; para uma DMU ineficiente, os valores de $\lambda$ serão os pesos utilizados na combinação linear de outras DMUs eficientes, que influenciam a projeção da DMU ineficiente sobre a fronteira calculada. Isso significa que, para uma unidade ineficiente, existe pelo menos uma unidade eficiente. As unidades eficientes serão os benchmarks das ineficientes.

Dessa forma, o modelo BCC, que pressupõe retornos variáveis à escala, introduz uma restrição de convexidade ao modelo CCR, apresentada em (5). 
Análise de eficiências técnica e de escala das indústrias do Pólo Moveleiro de Ubá Ana Cristina Miranda Rodrigues, Suely de Fátima Ramos Silveira, Daphine Alberti de Freitas, Luiz Antônio Abrantes, Marco Aurélio Marques Ferreira

$$
\begin{array}{cc}
\operatorname{MAX}_{\phi, \lambda} & \phi, \\
\text { sujeito } a & : \\
& -\phi y_{i}+Y \lambda \geq 0, \\
x_{i}-X \lambda \geq 0, & N_{1}{ }^{\prime} \lambda=1 ; \lambda \geq 0
\end{array}
$$


Análise de eficiências técnica e de escala das indústrias do Pólo Moveleiro de Ubá Ana Cristina Miranda Rodrigues, Suely de Fátima Ramos Silveira, Daphine Alberti de Freitas, Luiz Antônio Abrantes, Marco Aurélio Marques Ferreira

$O$ valor obtido para $\theta$ indica o escore de eficiência da $\mathrm{DMU}$, ou seja, um valor igual a 1 indica eficiência técnica da DMU em relação às demais, enquanto um valor menor do que 1 evidencia a presença de ineficiência técnica relativa. Caso a DMU seja ineficiente, os valores de $\square$ fornecem os "pares" daquela unidade, ou seja, as DMUs eficientes que serviram de referência para a DMU ineficiente.

Essa abordagem, segundo Gomes e Baptista (2004), forma uma superfície convexa de planos em interseção, a qual envolve os dados de forma mais compacta do que a superfície formada pelo modelo de retornos constantes. Com isso, os valores obtidos pela eficiência técnica, com a pressuposição de retornos variáveis, são maiores do que aqueles obtidos com retornos constantes. Além disso, o modelo DEA com orientação produto e pressuposição de retornos variáveis à escala, apresentado em (5), permite decompor a eficiência técnica em eficiência de escala e eficiência técnica com retornos variáveis.

A eficiência de escala faz uma projeção de quanto a empresa poderia ganhar se estivesse operando na escala ótima (neste caso, com retornos constantes); a eficiência técnica com retornos variáveis mede a quantidade utilizada de insumos, ou seja, a capacidade produtiva da empresa, caso estivesse utilizando corretamente seus insumos.

Ainda, segundo Gomes e Baptista (2004), se uma DMU é eficiente no modelo CCR, então também é eficiente no modelo BCC. Isso porque a medida de eficiência técnica obtida no modelo com retornos constantes é composta pela medida de eficiência técnica no modelo com retornos variáveis, que trata da pura eficiência técnica e da eficiência de escala.

\section{2 Área de estudos e fonte de dados}

Este estudo tem como referência as indústrias do setor moveleiro de Ubá, cadastradas no banco de dados do Sindicato Intermunicipal das Indústrias de Marcenaria da Ubá - INTERSIND. 
Análise de eficiências técnica e de escala das indústrias do Pólo Moveleiro de Ubá Ana Cristina Miranda Rodrigues, Suely de Fátima Ramos Silveira, Daphine Alberti de Freitas, Luiz Antônio Abrantes, Marco Aurélio Marques Ferreira

Embora o universo de indústrias deste Pólo seja numeroso, com, aproximadamente, 300 empresas, segundo a ABIMÓVEL (2006), este trabalho resultou de uma abordagem não- probabilística, que consiste em uma amostragem por conveniência. O convite à participação na pesquisa foi enviado a todas as empresas cadastradas no Intersind (108 empresas), no entanto, apenas 33 (trinta e três) se disponibilizaram a participar do estudo, fornecendo os dados quantitativos.

Segundo Hair et al. (2005), a amostra por conveniência envolve a seleção de elementos de amostra mais disponíveis para tomar parte no estudo e que podem oferecer as informações necessárias. Para Selltiz et al. (1987), a amostra deve ser feita quando o objetivo não é generalizar os resultados, mas sim obter boas ideias e opiniões críticas experientes, sendo recomendada para pesquisas nas quais 0 objetivo é o entendimento dos casos estudados.

O levantamento de dados e informações foi realizado por meio de questionário semi- estruturado, composto por questões fechadas e abertas, que possibilitou ao entrevistado complementar as respostas com considerações próprias. Todas as questões foram relacionadas ao problema estudado e formuladas de modo a responder os objetivos específicos estabelecidos.

O questionário foi aplicado como pré-teste em uma indústria moveleira, estabelecida na mesma região das escolhidas como participantes. O objetivo do préteste foi medir a eficiência das perguntas e o funcionamento efetivo para obtenção das respostas desejadas. Após sua aplicação e análise, foram efetuados os ajustes necessários para, em seguida, serem aplicados às indústrias escolhidas. Por meio do levantamento, buscou-se identificar e descrever o perfil de cada empresa participante do estudo e obter demais informações necessárias para o desenvolvimento da pesquisa.

Todos os questionários foram aplicados pelos pesquisadores, inclusive o préteste. As entrevistas foram apenas dialogadas, sem gravações, evitando constrangimentos aos entrevistados, uma vez que os proprietários reiteraram sigilo em 
Análise de eficiências técnica e de escala das indústrias do Pólo Moveleiro de Ubá Ana Cristina Miranda Rodrigues, Suely de Fátima Ramos Silveira, Daphine Alberti de Freitas, Luiz Antônio Abrantes, Marco Aurélio Marques Ferreira

relação às respostas. Este fato não criou vieses na eficiência da coleta de dados.

Para calcular as medidas de eficiência técnica e de escala para a amostra das indústrias moveleiras, foram utilizadas quatro variáveis, três delas relacionadas aos insumos e a outra relacionada ao produto. Segundo Gomes e Baptista (2004), as medidas de eficiência podem ser facilmente obtidas com poucos insumos e produtos. As variáveis analisadas foram:

Insumos: utilizados os componentes dos custos de produção anuais (em reais) matéria-prima, mão-de-obra e gastos gerais de fabricação, considerando que estes finalizam na forma de Estoques ou Custo dos Produtos Vendidos.

1) Matéria-prima: refere-se aos componentes utilizados para transformação em novos produtos.

2) Mão-de-obra direta: relacionado ao salário da mão-de-obra aplicada diretamente ao processo fabril, com os encargos trabalhistas e previdenciários.

3) Gastos gerais de fabricação: gastos incorridos para manutenção e funcionamento da indústria.

\section{Produto:}

1) Faturamento: indicador de ganho bruto anual, em reais, com a venda dos produtos fabricados, cujos insumos (custos) foram incidentes.

\section{RESULTADOS E DISCUSSÃO}

\subsection{A indústria moveleira no Brasil e em Ubá}

A indústria de móveis caracteriza-se, principalmente, por dois aspectos: elevado número de micro e pequenas empresas (familiares e de capital inteiramente nacional) e grande absorção de mão-de-obra. Assim, a atividade moveleira conta, aproximadamente, com 13.500 empresas, sendo, aproximadamente, 10 (dez) mil microempresas, 3 (três) mil pequenas empresas e, apenas, 500 (quinhentas) empresas 
Análise de eficiências técnica e de escala das indústrias do Pólo Moveleiro de Ubá Ana Cristina Miranda Rodrigues, Suely de Fátima Ramos Silveira, Daphine Alberti de Freitas, Luiz Antônio Abrantes, Marco Aurélio Marques Ferreira

de porte médio (Rosseto e Cruz, 2005; Silva e Câmara, 2004).

A atividade moveleira reúne diversos processos de produção, envolvendo diferentes matérias-primas e uma grande diversidade de produtos finais. Ela é segmentada, principalmente, em função de materiais com que os móveis são confeccionados (madeira, metal e outros) e os usos a que são destinados (em especial, móveis para residência e para escritório). Além disso, aspectos técnicos e mercadológicos das empresas condicionam a especialização em um ou dois tipos de móveis, por exemplo, de cozinha e banheiro (Gorine, 1998).

Segundo Gorine (1998), existem dois modelos organizacionais bem sucedidos na indústria moveleira europeia: o alemão, mais concentrado, onde predominam as empresas médias e grandes, cujas principais vantagens competitivas são baseadas em economias de escala, tanto na produção como na comercialização e no financiamento; e o italiano, baseado em pequenas firmas inovadoras (tecnologia e design), especializadas em determinados nichos e cujo tamanho reduzido implica maior flexibilidade para atender às variações da demanda.

De acordo com Câmara et al. (2008), em relação ao desenvolvimento dos polos moveleiros no Brasil e suas características de formação, é válido ressaltar que o modelo é diferente do alemão (grandes empresas) e do italiano (pequenas empresas associadas), configurando um polo misto. A competitividade da indústria moveleira brasileira pode ser ampliada em um ritmo mais intenso devido à crescente adoção de novas tecnologias, design diferenciado e suporte financeiro e estratégico para as empresas menores. Sua importância também é estratégica no que tange à geração de empregos porque é uma indústria intensiva em mão-de-obra.

O pólo moveleiro de Ubá está situado na Zona da Mata em Minas Gerais, sendo composto pelas cidades de Ubá (principal do pólo), Visconde do Rio Branco, São Geraldo, Tocantins, Piraúba, Rio Pomba, Rodeiro e Guidoval. Este pólo foi o primeiro do setor em Minas Gerais, sendo composto em sua maioria por micro e 
Análise de eficiências técnica e de escala das indústrias do Pólo Moveleiro de Ubá Ana Cristina Miranda Rodrigues, Suely de Fátima Ramos Silveira, Daphine Alberti de Freitas, Luiz Antônio Abrantes, Marco Aurélio Marques Ferreira

pequenas empresas, constituindo o mais importante do Estado e figura entre os sete mais importantes do país, com mais de 400 indústrias (Fernandes e Oliveira Júnior, 2002).

A exportação de móveis, em 2006 , respondeu por $43 \%$ de todos os produtos exportados pela região do polo de Ubá e por 31\% das exportações de móveis do Estado de Minas Gerais, totalizando mais de US\$ 6,3 milhões. Já em 2007, 0 crescimento das exportações, comparando-se com 2006, foi de 17,3\%, sendo exportados mais de US $\$ 7,6$ milhões, criando um saldo positivo de US\$1,1 milhão (FIEMG, 2008).

Os principais móveis fabricados pelas empresas analisadas são ilustrados na Tabela 1. O item "Outros" representa as empresas fabricantes de gaiolas e de aramados para móveis, produtoras de serragem de madeira, como, também, fábricas e acessórios para móveis. A madeira e o aço são os principais materiais usados na fabricação dos móveis.

Tabela 1 - Principais produtos fabricados pelo Pólo Moveleiro de Ubá

\begin{tabular}{cccc}
\hline Principais produtos & $\%$ & Principais produtos & $\%$ \\
\hline Salas de jantar & 14,7 & Gabinetes para cozinha & 2,9 \\
Dormitório & 14,7 & Móveis para escritório & 2,9 \\
Mesas e cadeiras & 8,8 & Toucador & 2,9 \\
Racks e estante & 8,8 & Cômoda & 2,9 \\
Cama & 5,9 & Sala & 2,9 \\
Guarda-roupas & 5,9 & Kit de cozinha & 2,9 \\
Cadeiras para decoração & 5,9 & Roupeiro & 2,9 \\
Estofados & 2,9 & Outros & 8,7 \\
Home & 2,9 & - & - \\
\hline
\end{tabular}

Fonte: Resultados da pesquisa

\subsection{Análise de eficiência da indústria moveleira}

O modelo DEA foi utilizado, inicialmente, pressupondo-se retornos constantes à escala, com objetivo de se obter a medida de eficiência técnica para cada indústria da amostra. Posteriormente, foi retirada a pressuposição de retornos constantes à escala, 
Análise de eficiências técnica e de escala das indústrias do Pólo Moveleiro de Ubá Ana Cristina Miranda Rodrigues, Suely de Fátima Ramos Silveira, Daphine Alberti de Freitas, Luiz Antônio Abrantes, Marco Aurélio Marques Ferreira

acrescentando- se uma restrição de convexidade, a qual possibilitou a obtenção das medidas de eficiência de retornos variáveis com orientação produto. Com essas duas medidas, foi possível calcular a eficiência de escala.

A Tabela 2 sintetiza os resultados obtidos, separando-se as indústrias moveleiras de acordo com as medidas de eficiência alcançadas.

Tabela 2 - Distribuição das indústrias moveleiras segundo escores de eficiência técnica e de escala, obtidos nos modelos DEA

\begin{tabular}{|c|c|c|c|}
\hline Empresa & $\begin{array}{c}\text { Eficiência } \\
\text { (retornos constantes) }\end{array}$ & $\begin{array}{l}\text { Eficiência (retornos } \\
\text { variáveis) }\end{array}$ & $\begin{array}{l}\text { Eficiência } \\
\text { de escala }\end{array}$ \\
\hline 1 & 0.544 & 0.684 & 0.795 \\
\hline 2 & 0.278 & 0.391 & 0.711 \\
\hline 3 & 0.339 & 0.723 & 0.469 \\
\hline 4 & 0.719 & 1.000 & 0.719 \\
\hline 5 & 0.953 & 1.000 & 0.953 \\
\hline 6 & 0.561 & 0.811 & 0.692 \\
\hline 7 & 0.384 & 0.811 & 0.473 \\
\hline 8 & 0.339 & 0.340 & 0.997 \\
\hline 9 & 0.509 & 0.914 & 0.557 \\
\hline 10 & 1.000 & 1.000 & 1.000 \\
\hline 11 & 0.770 & 0.885 & 0.870 \\
\hline 12 & 0.796 & 0.948 & 0.840 \\
\hline 13 & 0.293 & 0.603 & 0.486 \\
\hline 14 & 0.473 & 0.668 & 0.708 \\
\hline 15 & 0.520 & 0.528 & 0.985 \\
\hline 16 & 0.649 & 1.000 & 0.649 \\
\hline 17 & 0.340 & 0.405 & 0.839 \\
\hline 18 & 0.610 & 1.000 & 0.610 \\
\hline 19 & 0.466 & 0.864 & 0.540 \\
\hline 20 & 0.339 & 0.649 & 0.522 \\
\hline 21 & 1.000 & 1.000 & 1.000 \\
\hline 22 & 0.324 & 1.000 & 0.324 \\
\hline 23 & 0.425 & 1.000 & 0.425 \\
\hline 24 & 0.552 & 1.000 & 0.552 \\
\hline 25 & 0.451 & 0.456 & 0.990 \\
\hline 26 & 1.000 & 1.000 & 1.000 \\
\hline 27 & 1.000 & 1.000 & 1.000 \\
\hline 28 & 0.378 & 1.000 & 0.378 \\
\hline 29 & 0.526 & 0.588 & 0.895 \\
\hline 30 & 0.742 & 1.000 & 0.742 \\
\hline 31 & 0.534 & 0.549 & 0.974 \\
\hline 32 & 0.299 & 0.928 & 0.323 \\
\hline 33 & 0.614 & 1.000 & 0.614 \\
\hline$E=1,0$ & 4 & 14 & 4 \\
\hline Total & 33 & 33 & 33 \\
\hline Média & 0.567 & 0.810 & 0.716 \\
\hline Desvio-padrão & 0,229 & 0,220 & 0,223 \\
\hline
\end{tabular}

Fonte: Resultados da pesquisa. 
Análise de eficiências técnica e de escala das indústrias do Pólo Moveleiro de Ubá Ana Cristina Miranda Rodrigues, Suely de Fátima Ramos Silveira, Daphine Alberti de Freitas, Luiz Antônio Abrantes, Marco Aurélio Marques Ferreira

Sob a análise de retornos constantes à escala, verifica-se que, das 33 indústrias moveleiras da amostra, apenas quatro obtiveram máxima eficiência técnica e, por isso, estão operando sem problema de escala. A eficiência técnica total (retornos constantes) é composta pela eficiência técnica (retornos variáveis) e pela eficiência de escala.

O nível médio de ineficiência técnica desta medida é de $0,433(1-0,567)$. Como a ineficiência da empresa mede a quantidade que se pode expandir do produto (neste caso, o faturamento) sem mais insumos, as indústrias ineficientes podem, em média, expandir seu faturamento em $43,3 \%$, sem que seja necessário o aumento dos custos de produção.

É importante ressaltar que as indústrias moveleiras que alcançaram máxima eficiência técnica não podem expandir seu faturamento sem a introdução de mais insumos, pois já se encontram na fronteira eficiente. Entretanto, as demais podem fazê-lo, tendo como referência aquelas com eficiência técnica igual a um.

A ineficiência técnica com retornos variáveis mede a utilização excessiva de insumos, ou seja, a capacidade produtiva da empresa, caso ela estivesse utilizando corretamente seus insumos. Pela Tabela 2, pode-se identificar que 14 indústrias da amostra apresentaram máxima eficiência técnica com retornos variáveis e 19 diagnosticaram ineficiência na utilização de insumos, ou seja, dos custos de produção.

Em relação à eficiência de escala, que faz uma projeção de quanto a empresa poderia ganhar se estivesse operando na escala ótima (neste caso, com retornos constantes), apenas quatro demonstraram grau máximo $(1,0)$, estando, também, na fronteira de retornos constantes. Sendo assim, 29 empresas apresentaram operação de escala inapropriada (ineficiência de escala). As mesmas indústrias que estão operando com retornos constantes à escala, foram incluídas na escala ótima de produção (eficiência de escala), enquanto aquelas que operaram fora da faixa de retornos constantes de escala, também, não foram incluídas na escala ótima de 
Análise de eficiências técnica e de escala das indústrias do Pólo Moveleiro de Ubá Ana Cristina Miranda Rodrigues, Suely de Fátima Ramos Silveira, Daphine Alberti de Freitas, Luiz Antônio Abrantes, Marco Aurélio Marques Ferreira

produção.

As médias de pura eficiência técnica e de eficiência de escala são de 0,810 e 0,716, respectivamente. Isso significa que as indústrias ineficientes poderiam, em média, aumentar o faturamento em $19 \%$ otimizando corretamente os insumos. Se estivessem operando na escala correta, poderiam aumentar o faturamento em até $28,4 \%$, sem a necessidade de aumentarem os insumos.

Sendo assim, pode-se perceber que o problema das indústrias moveleiras ineficientes é a escala incorreta, apesar da utilização dos insumos necessitar de melhorias. Ou seja, há, proporcionalmente, mais problemas de escala que desperdício de insumos nas indústrias ineficientes.

Analisando o uso incorreto de insumo e a ineficiência de escala, os dados apresentados na Tabela 3 descrevem a situação média das empresas, em 2007. Verificada a participação dos custos de cada componente de produção em relação ao faturamento, pode-se perceber que nas empresas eficientes os custos da matériaprima, da mão-de-obra e dos gastos gerais de fabricação correspondem, respectivamente, a 9,5\%, 21,6\% e 7,7\%; nas empresas ineficientes, essas participações chegam a $24,7 \%, 14,5 \%$ e $13,4 \%$, respectivamente. As indústrias eficientes superam as ineficientes apenas nos custos relacionados à mão-de-obra.

Conforme mencionado, sob a condição de que não há desperdícios de insumos nas indústrias eficientes, elas não conseguem aumentar o faturamento com as atuais quantidades de insumos. Por outro lado, se as empresas ineficientes corrigirem seus problemas de utilização de insumo e de ineficiência de escala, poderão aumentar, em média, $19 \%$ e $28,4 \%$, respectivamente, o faturamento da empresa. 
Análise de eficiências técnica e de escala das indústrias do Pólo Moveleiro de Ubá Ana Cristina Miranda Rodrigues, Suely de Fátima Ramos Silveira, Daphine Alberti de Freitas, Luiz Antônio Abrantes, Marco Aurélio Marques Ferreira

Tabela 3 - Produto e insumos das indústrias moveleiras utilizadas na amostra, em 2007

\begin{tabular}{lcrrr}
\hline \multicolumn{1}{c}{ Especificação } & Unidade & Eficientes & \multicolumn{1}{c}{ Ineficientes } & \multicolumn{1}{c}{ Total } \\
\hline Faturamento bruto & $\mathrm{R} \$ /$ ano & $3.680 .172,25$ & $7.192 .483,58$ & $10.872 .655,83$ \\
Matéria-prima & $\mathrm{R} \$ / a n o$ & $349.390,39$ & $1.778 .582,41$ & $2.127 .972,80$ \\
Mão-de-obra & $\mathrm{R} \$ /$ ano & $796.216,45$ & $1.044 .337,19$ & $1.840 .553,64$ \\
Gastos gerais de fabricação & $\mathrm{R} \$$ /ano & $283.373,42$ & $961.568,63$ & $1.244 .942,05$ \\
Total de empresas & - & 4 & 29 & 33 \\
\hline
\end{tabular}

Fonte: Resultados da pesquisa.

Entretanto, a caracterização da ineficiência de uma empresa não é suficiente para orientá-la no sentido de melhorar seu grau de eficiência. É preciso identificar quanto desta ineficiência é proveniente da escala incorreta de produção e quanto poderia ser melhorado, caso sejam eliminados os excessos no uso dos insumos.

De acordo com a Tabela 2, das 31 empresas consideradas ineficientes, 14 apresentaram eficiência na utilização de insumos (eficiência técnica variável) e escala incorreta de produção (ineficiência de escala).

A ineficiência de escala pode ocorrer devido ao fato de a indústria moveleira operar abaixo da escala ótima (retornos crescentes) ou acima da escala ótima (retornos decrescentes). Se a empresa estiver abaixo da escala ótima, pode aumentar a produção a custos decrescentes, ou seja, ocorrerá economia de escala. Por outro lado, se estiver acima da escala ótima, o aumento na produção ocorrerá a custos crescentes, ou seja, haverá deseconomia de escala.

Para detectar se as ineficiências de escala são devidas ao fato de a indústria moveleira operar na faixa de retornos crescentes ou na faixa de retornos decrescentes, as empresas da amostra foram distribuídas segundo o tipo de retorno e o grau de pura eficiência técnica, conforme dados da Tabela 4.

Tabela 4 - Distribuição das indústrias moveleiras segundo o tipo de retorno e o grau de eficiência técnica

\begin{tabular}{cccc}
\hline Tipo de retorno & Eficientes & Ineficientes & Total \\
\hline Crescente & - & 8 & $8(24,2 \%)$
\end{tabular}


Análise de eficiências técnica e de escala das indústrias do Pólo Moveleiro de Ubá Ana Cristina Miranda Rodrigues, Suely de Fátima Ramos Silveira, Daphine Alberti de Freitas, Luiz Antônio Abrantes, Marco Aurélio Marques Ferreira

\begin{tabular}{cccc} 
Constante & 4 & - & $4(12,1 \%)$ \\
Decrescente & - & 21 & $21(63,7 \%)$ \\
Total & 4 & 29 & $33(100,0 \%)$ \\
\hline
\end{tabular}

Fonte: Resultados da pesquisa

Quanto ao tipo de retorno, a amostra de 33 indústrias do Pólo Moveleiro de Ubá pode ser assim distribuída: quatro empresas $(12,1 \%)$ se apresentaram eficientes, na faixa de retornos constantes (escala ótima); 31 empresas (93,9\%) apresentaram problemas técnicos e/ou de escala. Entretanto, é importante ressaltar que, das 31 empresas ineficientes, 8 delas encontraram-se na faixa de retornos crescentes, enquanto 21 se apresentaram com retornos decrescentes.

Os dados apresentados na Tabela 5 descrevem as médias do faturamento médio, insumos utilizados e grau de alavancagem operacionalizada, segundo o tipo de retorno à escala.

Tabela 5 - Produto e insumos das indústrias moveleiras segundo o tipo de retorno à escala

Tipo de retorno

\begin{tabular}{|c|c|c|c|c|}
\hline Especificação & Unidade & Crescente & Constante & Decrescente \\
\hline Faturamento Bruto & $\mathrm{R} \$ /$ ano & $629.083,38$ & $3.680 .172,25$ & $9.692 .826,51$ \\
\hline Matéria-prima média & $\mathrm{R} \$ /$ ano & $206.544,34$ & $349.390,39$ & $2.649 .681,11$ \\
\hline Mão-de-obra & $\mathrm{R} \$ /$ ano & $49.089,02$ & $796.216,45$ & $1.423 .479,35$ \\
\hline $\begin{array}{c}\text { Gastos gerais de fabricação } \\
\text { Grau de alavancagem } \\
\text { operacional }\end{array}$ & $\mathrm{R} \$ /$ ano & $60.868,32$ & $283.373,42$ & $1.304 .692,55$ \\
\hline & 1,75 & 1,35 & 1,58 \\
\hline
\end{tabular}

Fonte: Resultados de Pesquisa

Conforme esperado, as empresas abaixo da escala ótima de produção (retornos crescentes) possuem faturamento menor, grau de alavancagem operacional maior $(1,96)$ e, portanto, risco maior, enquanto aquelas que estão acima da escala ótima (retornos decrescentes) apresentam faturamento maior, grau de alavancagem operacional menor $(1,53)$ e risco menor. 
Análise de eficiências técnica e de escala das indústrias do Pólo Moveleiro de Ubá Ana Cristina Miranda Rodrigues, Suely de Fátima Ramos Silveira, Daphine Alberti de Freitas, Luiz Antônio Abrantes, Marco Aurélio Marques Ferreira

O faturamento médio das empresas que estão operando na escala ótima de produção é de $R \$ 3,7$ milhões/ano, grau de alavancagem operacional mais próximo de 1,0 , apresentando, pois, risco moderado.

\section{CONCLUSÃO}

Os resultados encontrados permitiram concluir que, sob a análise de retornos constantes à escala, das 33 indústrias moveleiras examinadas, apenas quatro obtiveram máxima eficiência técnica, operando sem problema de escala, mas não podendo expandir o faturamento sem aumento de seus custos de produção. Como a ineficiência da empresa mede a quantidade que se pode expandir do produto sem a necessidade de mais insumos, as indústrias ineficientes podem, em média, expandir seu faturamento em $43,3 \%$, sem que sejam necessários aumentos dos custos de produção.

Em relação à eficiência técnica com retornos variáveis, que medem a utilização de insumos, pôde-se identificar que 14 empresas da amostra apresentaram eficiência máxima. Quanto às demais (19 empresas), diagnosticadas como ineficientes, poderiam aumentar, em média, 19\% seu faturamento, caso utilizassem corretamente os insumos (sem excesso).

Quanto à eficiência de escala, que faz uma projeção de quanto a empresa poderia ganhar se estivesse operando na escala ótima (neste caso, com retornos constantes), apenas quatro demonstraram grau máximo $(1,0)$, estando também na fronteira de retornos constantes. Sendo assim, 29 empresas apresentaram operação de escala inapropriada (ineficiência de escala), podendo aumentar seu faturamento em $28,4 \%$ se estivessem operando em escala correta. As mesmas indústrias que estão operando com retornos constantes à escala foram incluídas na escala ótima de produção (eficiência de escala), enquanto aquelas que estão operando fora da faixa de retornos constantes de escala não foram incluídas na escala ótima de produção. Sendo assim, pode-se perceber que há, proporcionalmente, mais problemas de escala que 
Análise de eficiências técnica e de escala das indústrias do Pólo Moveleiro de Ubá Ana Cristina Miranda Rodrigues, Suely de Fátima Ramos Silveira, Daphine Alberti de Freitas, Luiz Antônio Abrantes, Marco Aurélio Marques Ferreira

desperdício de insumos nas indústrias ineficientes.

Em relação ao tipo de retorno, as quatro empresas eficientes $(12,1 \%)$ estão na faixa de retornos constantes (escala ótima). Entre as ineficientes, 8 (24,2\%) apresentam retornos crescentes e $21(63,7 \%)$ se encontram na faixa de retornos decrescentes. Conforme esperado, as empresas abaixo da escala ótima de produção (retornos crescentes) possuem faturamento menor e grau de alavancagem operacional maior, enquanto as que estão acima da escala ótima (retornos decrescentes) apresentam faturamento maior e grau de alavancagem operacional menor.

Assim, os resultados contribuíram para fortalecer as pressuposições de: (1) Oliveira (2002) e Ferreira (2005), ao tratarem eficiência como medida de rendimento individual dos componentes do sistema, sendo refletida pela melhor utilização das entradas para maximizar as saídas, considerando a tecnologia disponível; (2) Hansen e Mowen (2001), ao considerarem que eficiência e resultado estão fortemente vinculados ao processo de gestão de custos; (3) Dudick (1974), ao defender que as indústrias consumidoras em escala de materiais e componentes para produtos precisam estruturar e implantar um sistema de apuração de custos desses componentes para obter informações do quanto custam seus produtos e atividades, considerando que uma das importantes causas dos maus resultados financeiros e do insucesso da empresa é a falta de conhecimentos dos custos de produção;

(4) Eidt (2006), ao afirmar que a lucratividade nem sempre se realiza pelo aumento dos preços, uma vez que nem toda pretensão de aumentar o preço é exequível, mas, principalmente, pela economia e redução de custos e despesas.

\section{REFERÊNCIAS}

Associação Brasileira das Indústrias do Mobiliário - ABIMÓVEL. Panorama do setor moveleiro. Disponível em http://www.abimovel.com/?pg=panorama_setor>, acesso em 15/03/2008. 
Análise de eficiências técnica e de escala das indústrias do Pólo Moveleiro de Ubá Ana Cristina Miranda Rodrigues, Suely de Fátima Ramos Silveira, Daphine Alberti de Freitas, Luiz Antônio Abrantes, Marco Aurélio Marques Ferreira

BOWLIN, W.F. 1998. Measuring performance: an introduction to data envelopment analysis (DEA). Journal of Costs Analysis and Management. Fall, p. 3-27.

CÂMARA, M.R.G.; STEFANO, S.R.; DUTRA, I.S.; GIMENEZ, F.A.P.; ALIGLERI, L.A.; GUERREIRO, G.A.; SOUZA, N.M. e SCARAMUZZA, B.C. 2003. Cluster moveleiro no Norte do Paraná e o sistema local de disseminação de inovações. In: VI SEMEAD - Seminário em Administração FEA/USP. São Paulo, 2003. Disponível em http: www.ead.fea.usp.br/semead/6semead/PNEE/> acesso em 20 jun. 2008.

CHARNES, A.; COOPER, W.W.; LEWIN, A.Y. e SEIFORD, L.M. 1994. Data envelopment analysis: theory, methodology and application. Dordrecht: Kluwer Academic, 487p.

COOPER, W.W., SEIFORD, L.M. e TONE, K. 2000. Data envelopment analysis: a comprehensive text with models, applications, references and DEA-Solver software. Norwell, Massachusetts: Kluwer Academic Publishers, 318p.

DUDICK, T.S. 1974. Controle de custos industriais. Tradução Danilo A. Nogueira. São Paulo: Atlas.

EIDT, J. 2006. Gestão de custos em indústrias do setor moveleiro estabelecidas na região do Oeste do Estado de Santa Catarina: um estudo multicasos. Dissertação de Mestrado. Universidade Regional de Blumenau, Blumenau - FURB, 233p.

Federação das Indústrias do Estado de Minas GERAIS - FIEMG. Exportação. Disponível em http://www.fiemg.org.br/Default.aspx?tabid=38>, acesso em 10/06/2008.

FERNANDES, C.L. de L. e OLIVEIRA JÚNIOR, R.H. 2002. Cluster no setor moveleiro: um estudo das potencialidades da região de Ubá (MG). In: X Seminário sobre Economia Mineira.

FERREIRA, M.A.M. 2005. Eficiência técnica e de escala de cooperativas e sociedades de capital na indústria de laticínios do Brasil. Tese de Doutorado. Universidade Federal de Viçosa - UFV.

FRANCO, H. 1996. Contabilidade industrial. $9^{\circ}$ Ed, São Paulo: Atlas, 301p.

GOMES, A.P. e BAPTISTA, A.J.M. dos S. 2004. "Análise envoltória de dados: conceitos e modelo básicos". In: SANTOS, M. L. dos; VIEIRA, W. da C. (Orgs.). 
Análise de eficiências técnica e de escala das indústrias do Pólo Moveleiro de Ubá Ana Cristina Miranda Rodrigues, Suely de Fátima Ramos Silveira, Daphine Alberti de Freitas, Luiz Antônio Abrantes, Marco Aurélio Marques Ferreira

Métodos quantitativos em Economia. Viçosa: Editora UFV, 653 p.

GORINE, A.P. 1998. Panorama do setor moveleiro no Brasil, com ênfase na competitividade externa a partir do desenvolvimento da cadeia industrial de produtos sólidos de madeira. Rio de Janeiro: BNDES, 1998. (Panorama Setorial, 8).

HAIR Jr., J.F.; BABIN, B.; MONEY, A.H. e SAMOUEL, P. 2005. Fundamentos de métodos de pesquisa em Administração. Tradução Lene Belon Ribeiro. Porto Alegre: Bookman, 472p.

HANSEN, D.R.; MOWEN, M.M. Gestão de custos: contabilidade e controle. Tradução Robert Brian Taylor. São Paulo: Pioneira, 2001.

IBGE - Pesquisa Industrial Mensal Produção Física - Brasil. Disponível em http://www.ibge.gov.br/home/estatistica/indicadores/industria/pimpfbr/pimpfbr_2007 12_3.shtm, acesso em 21 jun. 2008.

KHOURY, C.Y. e ANCELEVICZ, J. 1999. A utilização do sistema de custos ABC no Brasil. Revista de Administração de Empresas REA, São Paulo, 39(1):55-63, jan.-mar.

LEONE, George Sebastião Guerra. 2000. Custos: planejamento, implantação e controle. 3. ed. São Paulo: Atlas, 520p.

MILLER, R.L. 1981. Microeconomia: teoria, questões e aplicação. Tradução Sara Gedanke. São Paulo: McGraw-Hill do Brasil, 507 p.

OLIVEIRA, D. de P.R. de. 2002. Sistema, organização e métodos: uma abordagem gerencial. $13^{\circ}$ ed. São Paulo: Atlas, 505 p.

PINDYCK, R.S. e RUBINFELD. D.L. 2005. Microeconomia. Tradução Eleutério Prado e Thelma Guimarães. $6^{\circ}$ ed. São Paulo: Pearson Prentice Hall, 672 p.

ROSSETO, C. R. e CRUZ, C.M.L. 2005. O estudo da indústria de móveis de Lagoa Vermelha, baseado na competitividade sistêmica, segundo modelo IAD, na percepção dos representantes do nível micro. Passo Fundo: UPF, v.13, $20 \mathrm{p}$.

SEIFORD, L.M. e THRALL, R.M. 1990. Recent developments in DEA: the mathematical programming approach to frontier analysis. Journal of Econometrics, (46):7-38. 
Análise de eficiências técnica e de escala das indústrias do Pólo Moveleiro de Ubá Ana Cristina Miranda Rodrigues, Suely de Fátima Ramos Silveira, Daphine Alberti de Freitas, Luiz Antônio Abrantes, Marco Aurélio Marques Ferreira

SELLTIZ, C.; WRIHTSMAN, L.S. e COOK, S.W. 1987. Métodos de pesquisa nas relações sociais. Tradução Maria Martha Hübner D'Oliveira, Miriam Marinotti Del Rey. $2^{\circ}$ ed. São Paulo: EPU, 150 p.

SILVA, V.M.R. da e CÂMARA, M.R.G. da. 2008. A indústria de móveis em Londrina. Semina: Ciências Sociais e Humanas, Londrina, v. 25, p. 43-56, set. 2004. Disponível em http://www.uel.br/proppg/semina/pdf/semina_25_1_21_34.pdf>, acesso em 25/05/2008.

TRIOLA, M.F. 2005. Introdução à Estatística. $9^{\circ}$ ed. Tradução Vera Regina Lima de Farias e Flores. Rio de Janeiro: LTC, 682p.

WESTON, J.F. e BRIGHAM, E.F. 2000. Fundamentos da administração financeira. $10^{\circ}$ ed. Tradução Sidney Stancatti. São Paulo: Pearson Education do Brasil, 1050p.

\footnotetext{
i A Confederação Nacional da Indústria do Brasil conceitua cluster como agrupamento, numa referência geográfica, a aglomeração de empresas ali localizadas que desenvolvem suas atividades de forma articulada e com uma lógica econômica comum, a partir, por exemplo, de uma dada dotação de recursos naturais, da existência de capacidade laboral, tecnológica ou empresarial local, e da afinidade setorial dos seus produtos (ABIMÓVEL, 2008).

iI A posição sobre a fronteira é condição necessária, mas não suficiente, para eficiência, pois, além de estar sobre a fronteira de eficiência, é necessária ainda a inexistência de desperdício na firma, caracterizada pela soma das variáveis de folga igual a zero (SEIFORD; THRALL, 1990).

iii A produção virtual advém da combinação de duas DMUs para formar uma DMU composta (virtual), que utiliza uma combinação de insumos para produzir uma combinação de produtos. Desde que essa DMU não, necessariamente, exista, ela é denominada DMU virtual. A ideia central é encontrar a melhor DMU virtual para cada DMU real (GOMES e BAPTISTA, 2004).

iv $\mathrm{O}$ grau de alavancagem operacional (GAO) se refere à mudança no lucro operacional resultante de uma determinada mudança percentual nas vendas (WESTON e BRIGHAM, 2000).
} 